\title{
Tough job market pushes more surgical specialists to extend training
}

\author{
n Cite as: CMAJ 2018 March 5;190:E273. doi: 10.1503/cmaj.109-5566
}

Posted on cmajnews.com on Feb. 15, 2018.

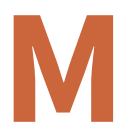

ore residents in specialties with limited job opportunities are extending their training by pursuing fellowships, according to data from the Canadian Post-MD Education Registry (CAPER). Meanwhile, the percentage of family medicine trainees taking an extra year to subspecialize has plateaued.

The past decade has seen increasing employment challenges for cardiac surgeons, otolaryngologists, orthopedic surgeons and radiation oncologists. These specialties have also seen increases in the proportion of trainees doing fellowships, delaying their entry to practice by a year or more.

"I think they feel it increases their chances, and what else are they going to do if they can't get a full-time position right away?" said Lynda Buske, manager of CAPER. "By taking a fellowship, you're continuing to work and keeping up your skills, and gaining more specialized skills to hopefully become more competitive."

However, "the worry with some of them becoming even more specialized is that it becomes harder to get them to rural areas," where the available jobs are often located, said Buske.

Orthopedic surgery and radiation oncology saw the biggest increases in fellows. In 2016, there were 85 orthopedic fellows and 24 radiation oncology fellows, representing $19.9 \%$ and $18.5 \%$ of all trainees in those specialties, respectively. That's up from 35 and 12 fellows a decade before, representing $10.8 \%$ and $7.4 \%$ of trainees.

With orthopedic surgery in particular, "it's not that the need isn't there; it's the infrastructure and operating room time and all those supports that aren't there," said Buske. "You can't hang your shingle if you don't have access to an operating room."

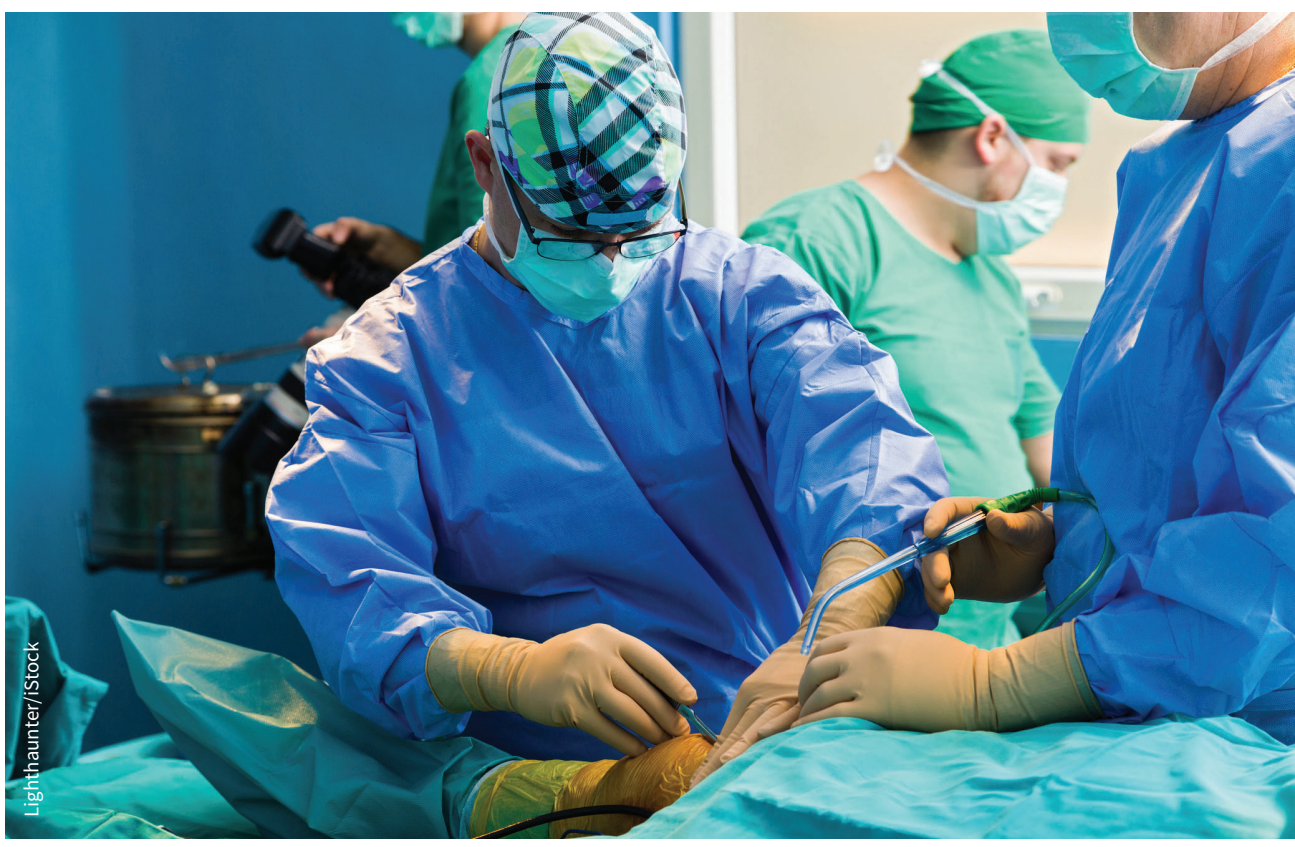

Nearly $20 \%$ of orthopedic trainees are doing fellowships after residency, double the rate from a decade ago.

The numbers for other specialties are smaller and harder to interpret, she added. There were 10 cardiac surgery fellows and 11 otolaryngology fellows last year, representing $13.7 \%$ and $6.6 \%$ of all trainees in those specialties, respectively. That's an increase from four and six fellows in 2006, representing $7.3 \%$ and $5 \%$ of trainees.

Some specialties have also seen increases in the average time spent in postgraduate training over the past decade. Notably, cardiac surgeons now spend an average of eight years to complete specialty training, up from 6.9 years a decade ago. Orthopedic surgeons and urologists spend an average of 6.0 and 5.7 years, respectively, up from 5.9 and 5.5 in 2006.

Meanwhile, family medicine has seen a levelling out of the percentage of trainees taking an extra year to subspecialize, after a peak of $23.1 \%$ in 2010 . At that time, "there was a big focus on specialization and everybody was catching onto that trend," said Buske. However, the pendulum has swung back over the past three years. In 2016, $19.4 \%$ of family medicine trainees took an extra year, returning to the pre-2009 norm. Then and now, the most of those trainees subspecialize in emergency medicine, care of the elderly, and palliative care.

Buske partly attributes the plateau to a concerted push by the College of Family Physicians of Canada to promote "cradle to grave" generalist care. "They don't want all the family physicians to go into emergency medicine or sports medicine," she explained. That said, "we're in a society of more and more specialization, so l'd be surprised if it went down further."

Lauren Vogel, CMAJ 